\title{
The Challenge of Integrating Non-Continuous Processes - Milk Powder Plant Case Study
}

\author{
Martin Atkins, Michael Walmsley, James Neale \\ Energy Research Group, University of Waikato \\ Private Bag 3105, Hamilton, New Zealand
}

The integration of non-continuous processes such as a milk powder plant present a challenge for existing process integration techniques. Current techniques are generally based on steady and continuous operation which for some industries is not the case. Milk production varies considerably during the year as dairy cows in New Zealand are grazed on pasture, which affects the scheduling and operation of plants on site. The frequency and duration of cleaning cycles and non-productive operating states can have a major affect on energy demand and the availability of heat sources and heat sinks. In this paper the potential for indirect heat transfer between the several plants using a heat recovery loop and stratified tank at a typical New Zealand dairy factory is investigated. The maximum amount of heat recovery is calculated for a range of recirculation loop temperatures. The maximum amount of heat recovery can be increased considerably if the temperature of the hot fluid in the recirculation loop is varied depending on which condition the site is operating under.

\section{Introduction}

The integration of semi and non-continuous processes using pinch analysis techniques has not received the same amount of attention as continuous and batch processes and as a consequence methods to examine non-continuous processes are not well developed. The integration of batch processes have typically employed the Time Slice Model (TSM) approach developed by Kemp \& MacDonald $(1987,1988)$ and later expanded by Kemp \& Deacon (1989). Various programming techniques such as Mixed Integer Linear Programming (MILP) have also been applied to improve the integration of batch processes by attempting to optimize the scheduling and Heat Exchanger Network (HEN) design (Vaselenak et al., 1986; Lee \& Reklaitis, 1995a; Foo et al., 2008). The basis for integrating batch processes is that the process is operated in a cyclic fashion and the scheduling of the operations are interdependent and constrained. Rescheduling of the operations may be permitted depending on the constraints of the process and final product. In the case of non-continuous operations, such as dairy factory producing multiple products, several semi-continuous plants operate independently. Unlike a batch process the scheduling of when each plant operates is a less regular depending on milk production and product demand. As there is usually a certain amount of intra-plant integration the next step to realise energy savings is to focus on inter-plant integration, 
however the issue of integrating between plants that operate non-regularly needs to be addressed. This paper will use a typical New Zealand dairy factory to examine and offer some possible solutions to the challenges of integrating non-continuous processes. The use of indirect heat transfer between plants utilising a recirculating heat recovery loop and thermal storage will be discussed as a practical solution for increase energy efficiency.

\section{New Zealand Dairy Industry}

The dairy industry is by far the largest industry in New Zealand. It generates a significant portion of New Zealand's export earnings and approximately $95 \%$ of the total milk produced is exported with around $90 \%$ of this as milk powder. Several other dairy products such as butter and cheese are produced although the production of milk powder is the most energy intensive process. From June 2006 - June 2007 there was $15,600,000$ metric tons of milk processed and 996,040 tons of milk powder produced nationally. Dairy cows in New Zealand are grazed on pasture and therefore the quantity of milk produced varies during the year with peak milk production typically occurring in late spring. Fig. 1 illustrates the milk production capacity of a typical dairy factory considered in this paper as a percentage of the maximum processing capacity.

\section{Typical NZ Milk Powder Plant}

For this study a typical New Zealand milk powder plant is considered. The factory processes around 8 million litres of milk at peak production and produces about 250,000 tons of milk powder and 85,000 tons of cream products annually. There are five separate plants on site: three milk powder plants, Anhydrous Milk Fat (AMF)/butter, and cream products. A schematic of the factory is shown in Fig. 2. The raw milk is separated into skimmed milk, which is used to feed the powder plants, and cream used to make AMF, butter and other cream products.

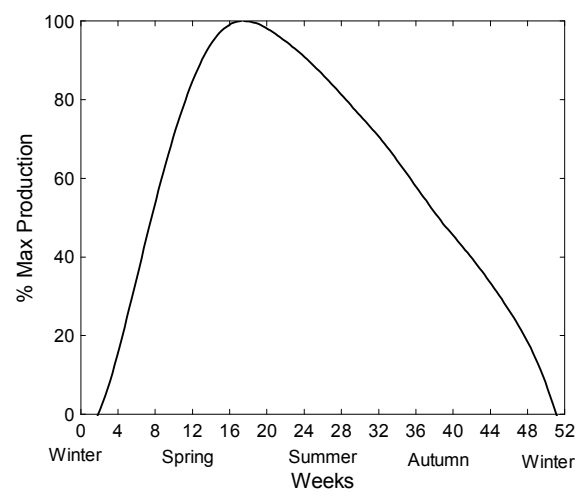

Figure 1. Milk production during the year.

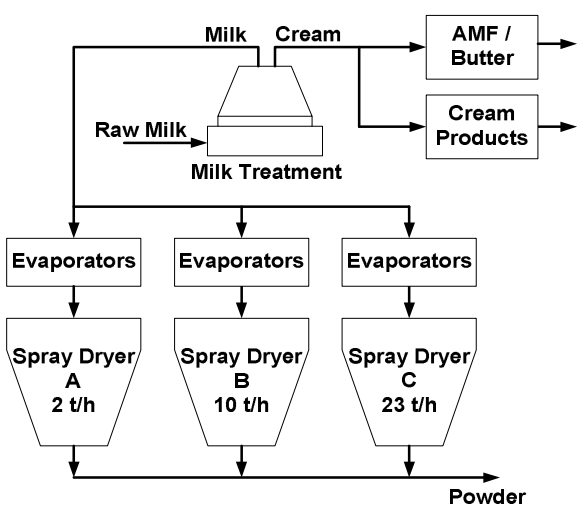

Figure 2. Schematic of the dairy factory with the five separate plants. 
Under normal production conditions each plant is operated in a semi-continuous manner because the process equipment must be cleaned regularly to ensure that product is fit for consumption and of an acceptable quality. For example, the spray dryers that produce milk powder can be either on product, offline, cleaning cycle (CIP), warm running (hot air is feed to the dryer but no feed is added), or water running (water is sprayed into the dryer instead of milk concentrate). Typical operating states for a two week period for Dryer B are shown on the left in Fig. 3 and illustrate that the dryer is frequently shifting between several operational states depending on the availability of raw milk and condition of the equipment. Superimposed on the semi-continuous operation of the several plants is the scheduling of the operation of the separate plants themselves. Due to the variation in the milk production, as discussed previously, not all of the plants may necessarily be operating at the same time. A representative production schedule for the entire factory is shown on the right in Fig. 3 with the four operating conditions indicated. During peak milk production all five plants operate as denoted by condition $\mathrm{D}$ in Fig. 3. The schedule presented here is a representative one and depending on annual milk production and consumer demand this schedule may differ somewhat to the one presented here. It should also be noted that there is the capability to vary the production rate of each plant to some extent depending on availability of milk.

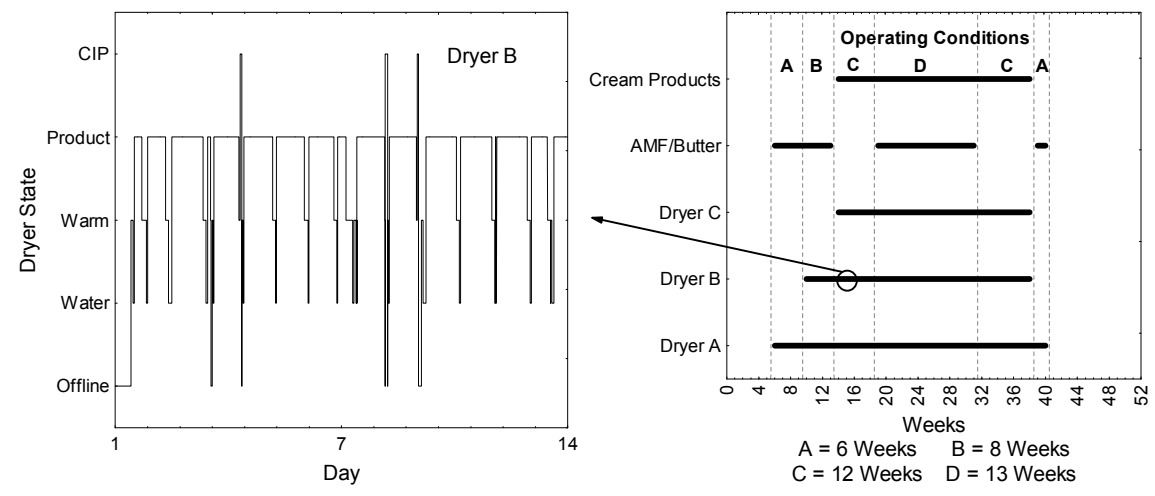

Figure 3. Semi-continuous operation of Dryer B (left) and a representative operating schedule (right) indicating the four operating conditions of the factory.

\section{Heat Recovery Loop with Thermal Storage}

By reason of the fact that each plant is operated under semi-continuous conditions and the total site is non-continuous in nature, direct integration between plants is difficult. One method to overcome this obstacle is to use indirect heat transfer via a recirculating system or Heat Recovery Loop (HRL) (Kemp, 2007). A thermally stratified tank (ST) can also be used as a thermal storage medium and a buffer to smooth any disturbances from plants going into different operational states like a cleaning cycle for example. The ST exploits a density difference of the fluid due to a difference in temperature thus creating natural stratification within the tank. The temperature in the tank will therefore 
vary along the height of the tank creating three regions, a region of higher temperature fluid $\mathrm{T}_{\text {hot }}$, a region of lower temperature fluid $\mathrm{T}_{\text {cold }}$, and a thermocline region where the temperature varies between $\mathrm{T}_{\text {hot }}$ and $\mathrm{T}_{\text {cold. }}$. HRL and $\mathrm{ST}$ systems such as these have been utilised at some dairy factories in NZ with significant energy savings being realised. A schematic of a HRL and ST is shown in Fig. 4 where the hot temperature fluid is pumped around the hot side of the loop (left side) and is used to heat cold streams or sinks. This fluid is then returned to the bottom of the $\mathrm{ST}$ at $\mathrm{T}_{\text {cold. }}$. At the same time cold fluid is also pumped around the cooling side of the loop and used to cool hot streams or sources with the fluid returning to the top of the $\mathrm{ST}$ at $\mathrm{T}_{\text {hot }}$. It is important over the long term that the total heating and cooling loads are balanced otherwise the ST will eventually fill with hot or cold fluid. To control the level of the thermocline and size of the hot and cold regions the individual heat exchangers can be operated at a reduced duty or disconnected from the loop with any deficit being made up with utility. Overtime the thermocline will grow and so there needs to be strategies in place to control the growth of the thermocline (Atkins et al., 2008).

There are several important issues to consider when evaluating the viability of a HRL and ST. One of the most important is determining how much heat can be recovered and reused elsewhere. Directly related to this is determining what temperature levels the HRL and ST operate at. Composite curves can be used to quickly determine the amount of maximum heat recovery (MHR) for a given $\mathrm{T}_{\text {hot }}$. However, for the correct MHR to be calculated from the composite curves, only those streams that satisfy the following criteria can be included in the composite curves, where $\mathrm{T}_{\text {in }}$ and $\mathrm{T}_{\text {out }}$ are the inlet and outlet temperatures of the process streams of the heat exchanger:

Hot streams (sources): $\mathrm{T}_{\mathrm{s}} \geq \mathrm{T}_{\text {hot }}+\Delta \mathrm{T}_{\text {min }}$ and $\mathrm{T}_{\text {in }} \geq \mathrm{T}_{\text {hot }}+\Delta \mathrm{T}_{\text {min }}$ and $\mathrm{T}_{\text {out }} \geq \mathrm{T}_{\text {cold }}+\Delta \mathrm{T}_{\text {min }}$ Cold streams (sources): $\mathrm{T}_{\mathrm{s}} \leq \mathrm{T}_{\text {cold }}-\Delta \mathrm{T}_{\text {min }}$ and $\mathrm{T}_{\text {in }} \leq \mathrm{T}_{\text {cold }}-\Delta \mathrm{T}_{\text {min }}$ and $\mathrm{T}_{\text {out }} \leq \mathrm{T}_{\text {hot }}-\Delta \mathrm{T}_{\text {min }}$

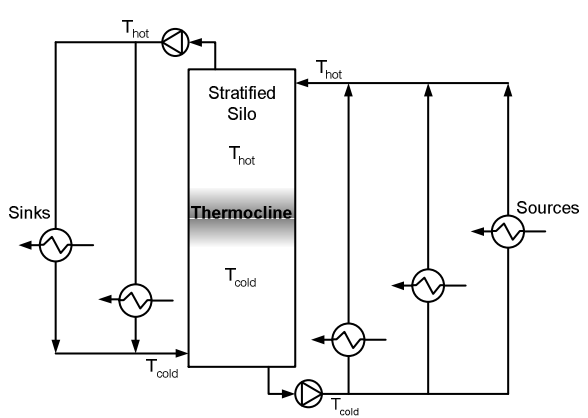

Figure 4. Schematic of the heat recovery loop including a stratified tank.

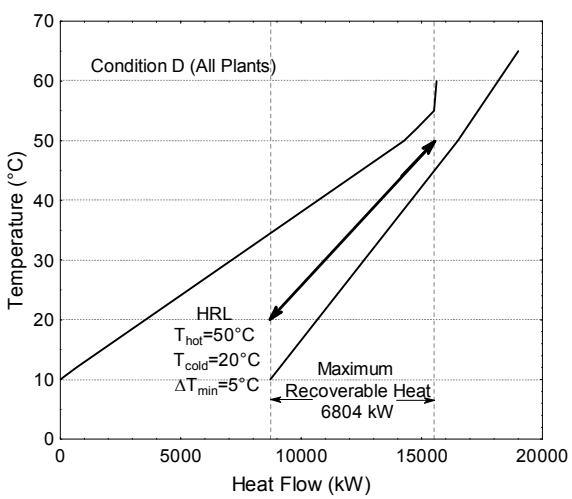

Figure 5. Composite curves showing indirect heat transfer between plants using HRL for condition D. 
Table 1. Stream data for potential streams for inclusion in the heat recovery loop.

\begin{tabular}{ccccccc}
\hline Stream Name & Plant & $\begin{array}{c}\text { Stream } \\
\text { Type }\end{array}$ & $\begin{array}{c}\mathbf{T}_{\mathbf{s}} \\
\left({ }^{\circ} \mathbf{C}\right)\end{array}$ & $\begin{array}{c}\mathbf{T}_{\mathbf{t}} \\
\left({ }^{\circ} \mathbf{C}\right)\end{array}$ & $\begin{array}{c}\mathbf{m C p} \\
\left(\mathbf{k W} /{ }^{\circ} \mathbf{C}\right)\end{array}$ & $\begin{array}{c}\text { Operating } \\
\text { Conditions }\end{array}$ \\
\hline Cow Water & Dryer A & Hot & 52 & 10 & 19.2 & A,B,C,D \\
Cow Water & Dryer B & Hot & 50 & 10 & 96.0 & B,C,D \\
Cow Water & Dryer C & Hot & 55 & 10 & 223.8 & C,D \\
AMF 1 & AMF & Hot & 60 & 12 & 18.6 & A,B,D \\
Site Hot Water & Site & Cold & 10 & 65 & 167.2 & A,B,C,D \\
Product Heating & Cream & Cold & 10 & 50 & 27.2 & C,D \\
\hline
\end{tabular}

The stream data for potential streams to be include in the HRL is given in Table 1. Fig. 5 shows the composite curves with fluid from the $\mathrm{HRL}$ at a $\mathrm{T}_{\text {hot }}=50^{\circ} \mathrm{C}$ and $\mathrm{T}_{\text {cold }}=20^{\circ} \mathrm{C}$. If $\mathrm{T}_{\text {hot }}$ is lowered to $45^{\circ} \mathrm{C}$ the MHR will reduce even though more sources become available and meet the criteria because MHR in this case is constrained by the number of sinks. The MHR at different $\mathrm{T}_{\text {hot }}$ is given in Fig. 6 for the four operating conditions and $\mathrm{T}_{\text {cold }}=20^{\circ} \mathrm{C}$. Conditions $\mathrm{C}$ and $\mathrm{D}$ have the same MHR but it varies substantially for condition $\mathrm{B}$.

The average heat recovery weighted for the number of weeks spent operating at each condition for a range of $\mathrm{T}_{\text {hot }}$ is shown by the solid line in Fig. 7. A maximum of $4,649 \mathrm{~kW}$ occurs if $\mathrm{T}_{\text {hot }}$ of the $\mathrm{ST}$ is at $45^{\circ} \mathrm{C}$. The assumption is that the plants run continuously when they are on, however this is not correct as each plant will be operating in a semi-continuous manner. The actual time a single heat exchanger might be operating in the HRL will depend on the operating cycle of the plant, and therefore the source or sink may only occur $85 \%$ of the time for example. The actual value will be somewhat less than what is shown here however the relative values are what are important.

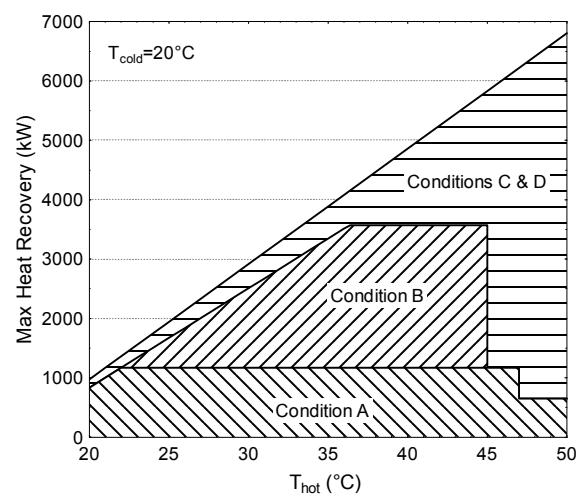

Figure 6. Effect of $T_{\text {hot }}$ on maximum heat recovery for the several operating conditions.

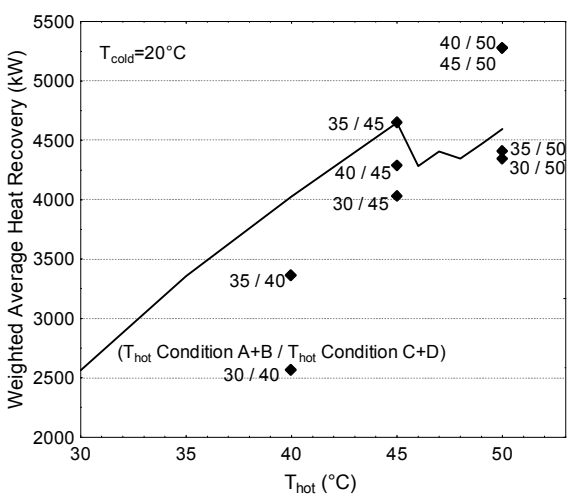

Figure 7. Weighted average heat recovery for all conditions with split HRL operating scenarios. 
There is also the option to alter $\mathrm{T}_{\text {hot }}$ of the ST depending on the operating condition and increase the amount of heat recovery. The solid data points shown in Fig. 7 specify the heat recovery potential of operating at one $\mathrm{T}_{\text {hot }}$ for conditions $\mathrm{A}$ and $\mathrm{B}$ and then a higher $\mathrm{T}_{\text {hot }}$ for conditions $\mathrm{C}$ and $\mathrm{D}$. If for conditions $\mathrm{A}$ and $\mathrm{B} \mathrm{T}_{\text {hot }}$ is 40 or $45^{\circ} \mathrm{C}$ and for conditions $\mathrm{C}$ and $\mathrm{D}$ the $\mathrm{T}_{\text {hot }}$ is $50^{\circ} \mathrm{C}$ then a significant increase in the amount of heat recovery occurs. This occurs because at the first two conditions the MHR is limited by the number of sources and therefore by lowering $\mathrm{T}_{\text {hot }}$ more streams become feasible. In the case of a $40 / 50$ split between operating conditions the average heat recovery increases by $13.4 \%$.

There are still many other aspects of the HRL and ST that need to considered, for example the economic trade off between heat exchanger area and heat recovery. Other important factors such as the correct sizing and design of the ST and recirculation loop also need to be considered, however these will be discussed in the future.

\section{Conclusions}

Integrating non-continuous processes such as a dairy factory is a challenge due to the irregular operation of the several plants on site. Direct heat transfer between plants is often impractical and therefore indirect heat transfer using a recirculating heat recovery loop is an alternative. Heat storage using a stratified tank is also an option to act as a buffer for when plants go onto a non-productive operating state. Traditional composite curves can be used to estimate the maximum heat recovery and to determine the optimal temperatures of the stratified tank. The maximum amount of heat recovery can be increased considerably if the temperature of the hot fluid in the recirculation loop is varied depending on which condition the site is operating under.

\section{References}

Atkins M.J., Morrison, A.S. and Walmsley M.R.W.W., 2008, Stratified Tanks for Heat Storage - Interface Control and Re-establishment. CHEMECA Conference, New Castle, Australia, September 2008.

Foo D.C.Y., Chew, Y.H., and Lee, C.T., 2008, Minimum units targeting and network evolution for batch heat exchanger network. Appl. Therm. Eng., 28:2089-2099.

Kemp I.C., 2007, Pinch analysis and process integration. Elsevier Ltd, Oxford, UK.

Kemp I.C., and Deakin A.W., 1989, The cascade analysis for energy and process integration of batch processes: Part 1 and 2. Chem. Eng. Res. \& Design, 67:495-516.

Kemp I.C., and MacDonald E.K., 1987, Energy and process integration in continuous and batch processes. IChemE Symp. Ser., 105:185-200.

Kemp I.C., and MacDonald E.K., 1988, Application of pinch technology to separation, reaction and batch processes. IChemE Symp. Ser., 109:239-257.

Lee B., and Reklaitis G.V., 1995, Optimal scheduling of cyclic batch processes for heat integration I. Comp. \& Chem. Eng., 19:883-905.

Vaselanak J.A., Grossmann I.E., and Westerberg A.W., 1986, Heat integration in batch processing. Ind. Eng. and Chem. Process Design and Development, 25:357-366. 